\title{
A AUTORIA NO ENLACE EQUÍVOCO DAS POSIÇÕES DE SUJEITO*
}

Suzy Lagazzi ${ }^{1}$

\section{Resumo}

A identificação de alunos e professores em diferentes posições de sujeito é o grande ponto de investimento deste texto no qual a preocupação principal fica sintetizada na pergunta: que posições são essas que compõem o cenário da prática docente? Tendo como perspectiva teórico-metodológica a Análise do Discurso Materialista, a autora se fundamenta em Pêcheux, Orlandi, Gallo, Pfeiffer, Fedatto e Machado. Considerando as condições de produção da prática docente, a autora entrelaça o conceito de posição de sujeito e a noção de equívoco para compreender a produção do conhecimento enquanto gesto de autoria. Assinala a necessária busca de condições para que o desejo de saber e a identificação com o conhecimento estejam em contradição com a hierarquia da autoridade de saber, de modo que a apropriação dessa autoridade passe a ser um processo de responsabilização dos sujeitos professores e alunos pelos sentidos.

Palavras-chave:Autoria; Equívoco; Discurso; Ensino; Posição de Sujeito

\footnotetext{
*O convite para compor este dossiê em homenagem a Regina Mutti, pesquisadora e docente que sempre fez da relação com o ensino o palco de sua reflexão, me levou de volta à discussão da autoria. Um retorno bem-vindo e que retoma algumas questões do minicurso por mim ministrado no VII SENALE, na UFPEL, em 2012. Agradeço o convite.

${ }^{1}$ Professora Doutora do Departamento de Linguística do Instituto de Estudos da Linguagem (IEL) da Unicamp. Rua Sérgio Buarque de Holanda, 571. Barão Geraldo, Campinas, SP. CEP 13083-859. slagazzi@gmail.com
} 


\section{INTRODUÇÃO}

A relação entre professor e aluno toca um ponto extremamente sensível do universo da produção do conhecimento pelo viés da autoria. Uma relação atravessada por diferentes determinaçõese palco de inúmeras discussões e propostas, que continua a demandar reflexão. Uma relação constitutivamente equívoca, no sentido discursivo do termo (PÊCHEUX, 1990), que nos apresenta os papéis institucionalmente reconhecidos de professor e aluno significados em diferentes posições de sujeito.

Ao afirmar a equivocidade constitutiva da linguagem, Michel Pêcheux fissurou a positividade da ciência, mostrando que o espaço da interpretação é um espaço de produção de conhecimento. As disciplinas de verificação, por muito tempo incontestes no mundo da cientificidade, foram pouco a pouco tendo suas fronteiras tocadas por perguntas que confrontavam a estabilidade disjuntiva do verdadeiro ou falso. No contraponto com a verificação lógica, o batimento entre descrição e interpretação permitiu que a produção do conhecimento fosse analisada no campo do político como uma "tomada de posição" do sujeito: "Face às interpretações sem margem nas quais o intérprete se coloca como um ponto absoluto, sem outro nem real, trata-se aí, para mim, de uma questão de ética e política: uma questão de responsabilidade.” (p.57).

Espaço aberto para a autoria, espaço produtivo para discutirmos a produção do conhecimento na equívoca relação entre alunos e professores identificados em diferentes posições de sujeito.Justamente essa identificação de alunos e professores em diferentes posições de sujeito será o grande ponto de investimento deste texto. Que posições são essas que compõem o cenário da prática docente?

A tomada do conceito de posição de sujeito pela noção de equívocoé importante para compreendermos a produção do conhecimento enquanto gesto de autoria e istoexige que busquemos as condições de produção da prática docente. Chego, então, à sala de aula.

Espaço legitimado na circulação do conhecimento,ela compõe o universo logicamente estabilizado da prática docente e está configurada em fronteiras que tendem a barrar a autoria. ${ }^{2} \mathrm{~A}$ produção do conhecimento como autoria possível requer a reorganização simbólicadas fronteiras que estruturam a prática docente na sala de aula e para isso a

${ }^{2}$ Cf. Lagazzi-Rodrigues (2003). 
'autoridade de saber' precisa ser apropriada pelo sujeito, que deve responsabilizar-se pelo seu dizer.

Autoria, autoridade, responsabilidade. Significantes em deriva que me levam areflexões fortes:Orlandi (1988), Gallo (1992), Pfeiffer (1995), Fedatto e Machado (2007). Textos que reiteram a importância do olhar discursivo para o ensino e para a escola.

Em discussão anterior (LAGAZZI, 2006) retomei as reflexões de Orlandi,Gallo e Pfeiffer para falar da autoria. Volto a Gallo, que ao discorrer sobre a necessidade da "assunção da autoria" na passagem do discurso da oralidade para o discurso da escrita, mostra exemplarmente, com sua experiência realizada na Escola do Sítio com alunos de 5 a . Série, o que significa reorganizar simbolicamente as fronteiras numa sala de aula. Ao solicitar dos alunos que produzissem um "fecho" para sua história,a professora Solange Gallo fez com que eles se apropriassem de suas histórias pela definição de um "efeito de fim". Ao terem que se assumir autores, os alunos se investiram da 'autoridadede saber'.

Fedatto e Machado analisam cenas de três filmes "que contrapõem diferentes modos de representar a autoridade no discurso pedagógico" (p.09) com o objetivo de "colocar em questão a relação autoritarismo-autoridade-autoria no espaço institucionalizado da sala de aula" (idem, ibidem): Pink Floyd - The Wall, de Alan Parker (1982), Sociedade dos Poetas Mortos, de Peter Weir (1989) e A Voz do Coração, de Christophe Barratier (2004). Dentre os pontos discutidos pelas autoras, quero salientar a afirmação de que "a relação professor-aluno na escola é um tema político". Fazendo ressoar a discussão de Pêcheux sobre o político, esta é uma consideração muito importante para a perspectiva discursiva materialista, pois desnaturalizaa produção do conhecimento na escola, mostrando as relações de força aí envolvidas, não apenas entre professores e alunos, mas no espaço complexo das instituições escolares e da sociedade.

As autoras provocam os leitores com várias questões que colocam em foco os verbos 'ensinar' e 'aprender', trazendo para a cena as formas de repetição empírica (exercício mnemônico), formal (restrita à paráfrase) e histórica (produz a inscrição do dizer no repetível enquanto memória constitutiva), tal qual propostas por Orlandi (1996, p.70).Desse trajeto, ressalto duas perguntas sobre as quais quero me deter:Como fica situada a possibilidade da autoria na sala de aula para professores e alunos?Como trazer a repetição histórica para a sala de aula, de maneira que permita a inscrição dos sentidos como conhecimento na história do sujeito-professor e do sujeito-aluno? 
LAGAZZI, Suzy.

Ao olhar para estas perguntas, um ponto sobressai: a autoria é questionada não só na relação com o aluno mas também com o professor. Pfeiffer (1995) contribuiu fortemente para essa discussão ao defender que não só o aluno fica barrado pelo livro didático em sua possibilidade de autoria, mas também o professor fica impedido de interpretar: "Quando falamos no livro didático, não estamos nos limitando ao seu uso empírico e concreto; estamos falando de uma prática mais geral que consiste na negação da entrada do professor e do aluno na posição de responsabilidade pelo gesto interpretativo" (p.74).

Essa posição de responsabilidade pelo gesto de interpretar, necessária para que a produção do conhecimento se inscreva fazendo história para os sujeitos aluno e professor, vem marcada na equivocidade dos verbos 'aprender' e 'ensinar'. Verbos que se contrapõem e se complementam na hierarquia imaginária do saber. Verbos que demandam o reconhecimento da alteridade na produção do conhecimento e na apropriação subjetiva da evidência de um conteúdo. Verbos que fazem transitar a autoridade entre o eu e o outro na imbricação do autoritarismo.

Portanto, pensar a produção do conhecimento sustentada na relação entre professor e aluno é necessariamente discutir a autoria comoresponsabilização pelos sentidos em seus limites e possibilidades. Isso significa considerar as diferentes ordens de determinações históricas que constituem essa relação e os pré-construídos mobilizados pela memória do dizer.

\section{POSIÇÃO DE SUJEITO E HIERARQUIA}

A hierarquia de saber entre professor e aluno é uma das determinações imaginárias mais naturalizadas na instituição escolar e na sala de aula. Fedatto e Machado discutem o autoritarismo no discurso pedagógico com base na tipologização proposta por Orlandi (1983), que caracteriza o discurso autoritário como "aquele em que a reversibilidade tende a zero" e “a polissemia é contida".As autoras afirmam que o discurso pedagógico "impede a legitimação de sentidos não-previstos”. Dessa forma, as repetições mnemônica e formal são as autorizadas no discurso pedagógico e é sempre o professor o responsável por legitimar a interpretação correta. Em termos de eficácia ideológica, é importante frisar que o autoritarismo no discurso pedagógico é muito reafirmado pelos professores, mastambém os 
alunos exigem do professor a autoridade desaber, eximindo-se de qualquer responsabilidade na repetição dos conhecimentospropostos.

Quando a hierarquia é sobredeterminante, 'ensinar' e 'aprender' configuram um par dicotômico sustentado por conteúdos logicamente estabilizados, as "coisas-a-saber" referidas por Pêcheux (1990, p.34), e professor e aluno constituem posições institucionais em oposição: o professor sabe, o aluno deve aprender, e consequentemente o professor não precisa aprender e o aluno não sabe. Afirmações estanques em via de mão única na circulação do conhecimento, sem espaço para que possamos perguntar sobre 'ensinar' e 'aprender'.

Nos moldes da pergunta de Pêcheux (p.24-25) sobre o enunciado “Ganhamos!” “Quem ganhou o quê?” -, Fedatto e Machado (p.09) perguntam: “Quem ensina o que para quem?" Questão tinhosa, que incide sobre as posições de sujeito em jogo no cenário da prática docente. Para além das respostas logicamente estabilizadas pela hierarquia da 'autoridade de saber', que outras respostas são possíveis a partir de que posições de sujeito? Como as posições de sujeito se configuram na equivocidade dos sentidos em cena?

Conceber o sujeito como posição significa pensá-lo em seus processos de identificação e no reconhecimento que constitui essa identificação. Algumas reiterações são importantes quando se fala da identificação do sujeito, como por exemplo "especificar que a identificação é um processo simbólico, que nos identificamos em relações significantes" (LAGAZZI, 2013a, p.313). Este ponto é fundamental para impedir qualquer leitura idealista, que ligue a identificação à vontade do sujeito. A identificação se dá como reconhecimento no desconhecimento. Vejamos:

Louis Althusser, em seu texto Freud e Lacan (1984), retoma Lacan para pontuar o que considera ser a grande contribuição e descoberta do autor e que diz respeito ao fato de que na passagem da existência biológica à existência humana, é sob a lei da linguagem que se fixa e se dá toda a ordem humana. Althusser fala dos dois grandes momentos dessa passagem. O primeiro, "o momento da relação dual", em que a criança vive com a mãe "essa relação dual no modo do fascínio imaginário do ego, sendo ela [a criança] [...] todos os outros da identificação narcísica primária, sem jamais poder tomar, face ao outro ou a si mesma, a distância objetivante do terceiro" (ALTHUSSER, 1984, p. 64).

O segundo momento, o "do Édipo", "no qual surge uma estrutura ternária no fundo da estrutura dual, quando o terceiro (o pai) se imiscui, como um intruso, na satisfação imaginária do fascínio dual, perturba a sua economia, quebra os seus fascínios, e introduz a criança nisso a que Lacan chama a Ordem Simbólica, a da linguagem objetivante, que lhe permitirá dizer finalmente: eu, tu, ele ou ela, que permitirá, pois, ao serzinho situar-se como criança humana num mundo de terceiros adultos." (ALTHUSSER, 1984, p.65). 
LAGAZZI, Suzy.

O primeiro momento, sintetiza Althusser, é o momento do imaginário e o segundo momento é o do simbólico, sendo que há um esclarecimento capital feito por Lacan: os "dois momentos são dominados e marcados por uma única Lei, a do Simbólico [...] sob a própria forma da Ordem do significante, ou seja, sob a forma de uma Ordem formalmente idêntica à ordem da linguagem" (idem, p. 65).

[...] Althusser ressalta que o discurso do Outro, do grande Terceiro que vem permitir a objetivação nas relações de linguagem, é o discurso do inconsciente, "condição absoluta de qualquer discurso" (idem, p.67).

Finalizando seu texto, Althusser retoma Freud para ressaltar "que o sujeito humano é descentrado, constituído por uma estrutura que também tem um 'centro' apenas no desconhecimento imaginário do 'eu', ou seja, nas formações ideológicas em que ele se "reconhece"' (idem, p.71). E (in)conclui falando da necessidade de melhor compreensão dessa estrutura do desconhecimento que tanto interessa "a qualquer pesquisa sobre a ideologia".

Quero chamar a atenção sobre o processo do reconhecimento, que se dá no desconhecimento. Desconhecimento imaginário que habita o "eu" em seu efeito de unidade, em suas certezas e na evidência dos sentidos. Desconhecimento da alteridade constitutiva do sujeito e dos sentidos. Desconhecimento de que o familiar e o estranho se entrelaçam nos efeitos metafórico e metonímico. Desconhecimento na linguagem do irrealizado da linguagem. Desconhecimento do discurso do inconsciente e de suas razões intangíveis: "só há causa daquilo que falha". (LAGAZZI, 2013a. p.315-317.)

Recorro a esta citação que reúne explicações, a meu ver, esclarecedoras para falar do reconhecimento no processo da identificação do sujeito. É importante compreender que ser sujeito de linguagem é estar constituído na Lei do Simbólico sob a ordem do significante, numa relação de linguagem objetivante inconsciente. Não há qualquer domínio do sujeito sobre esse processo, e as escolhas são as possíveis em um conjunto já determinado. Identificar-se é se reconhecer na evidência de sentidos que se produzem no movimento da cadeia significante, portanto se desconhecendo a cada reconhecimento já que a falta é constitutiva nesse processo. Como o reconhecimento nunca se completa, ele se abre em desconhecimento.

$\mathrm{Na}$ identificação com a hierarquia institucionalizada da autoridade imaginária de saber, os sujeitos em cena na prática docente ficam colados aos lugares institucionais do professor e do aluno,em oposição um ao outro, na evidência da transmissão hierarquizada de conteúdos estabilizados. O saber legitimado e localizado no professor é o pré-construído que, nesse caso,recorta amemória do dizer na atualização do discurso pedagógico, constituindouma posição de sujeito determinada pela hierarquia da autoridade de saber. Uma formação discursivana qual as posições institucionais de aluno e professor atualizam, na oposição,uma 
única posição de sujeito do discurso. Uma mesma posição de sujeito para professores e alunos.

“Quem ensina o que para quem?”Já conhecemos a resposta a essa pergunta a partir de uma posição de sujeitoconstituída sob a determinaçãoda hierarquia da autoridade de saber.Uma determinação definidora nessecenário da prática docente atravessado por contradições. Se por um lado a hierarquia produz atualizações dicotômicas, por outro, o desejo de saber e a reverência ao conhecimento produzem a convergência entre professores e alunos, em relações que os identificam numa mesma posição de sujeito, distinta da posição de sujeito da hierarquia. Reconhecer a importância do conhecimento sustenta as instituições educacionais, as relações de ensino/aprendizageme a sala de aula. Essa posição de sujeito do conhecimento, que tem como pré-construído a importância do conhecimento,é condição para o discurso pedagógico.Alunos e professores, antes de se identificarem com a divisão do saber, precisam se identificar com a importância de saber e do saber. Mesmo o exercício mnemônico da repetição empírica ou a repetição formalse sustentam na identificação com a importância do conhecimento. E, portanto, ela também é condição para a autoria. Estando numa ordem discursiva diferente da ordem da hierarquia, a identificação com o conhecimento abre a possibilidade de produzir autoria. Ao mesmo tempo condição e possibilidade da autoria.

Assim, julgo fundamental buscar condições para que o desejo de saber e a identificação com o conhecimento estejam em contradição com a hierarquia da autoridade de saber. Desestabilizar a sobredeterminação da hierarquia. Fazer funcionar o equívoco na autoridade.

\section{DA HIERARQUIA PARA A AUTORIA}

“Quem ensina o que para quem?” A partir da posição de sujeito do conhecimento a equivocidade toma força nesta pergunta. Não mais a evidência da transmissão hierarquizada de conteúdos estabilizados tendo como ponto de referência o professor. A pergunta passa a fazer sentido nela mesma e as respostas possíveis são contextualizações em movimento, diferentes condições de produção que se configuram. Os protagonistas da 'autoridade de saber' não ficam pré-determinados por uma legitimação institucional. A apropriação da autoridade de saber e poder dizer passa a ser um processo de responsabilização dos sujeitos 
professores e alunos pelos sentidos, tal como lemos em Orlandi (1988), Gallo (1992) e Pfeiffer (1995). Entramos no escopo da produção do conhecimento pelo gesto da autoria.

Nesse enlace equívoco entre autoridade e autoria quero voltar às cenas analisadas porFedatto e Machado(idem).

Pink Floyd - The Wallapresenta a relação mais radical com o autoritarismo pedagógico e a hierarquia não só de saber mas também de poder. A autoridade fica sobredeterminada pelo autoritarismo, como nos mostram Fedatto e Machado. A cena selecionada e analisada pelas autoras mostra Pink numa aula de matemática sendo ridicularizado pelo professor, que o flagra escrevendo uma poesia. Os alunos são instados pelo professor a repetir mnemonicamente postulados matemáticos, numa reiteração do mesmo que acompanha a ordenação das fileiras na sala de aula, os alunos uniformizados, as vozes em uníssono. Temos um filme no qual a reversibilidade e a polissemia estãoanuladas. Quando acontece a insurreição por parte dos alunos, numa resposta tão radical quanto a repressão mantida, o autoritarismo fica transferido e as relações de poder invertidas,com a reversibilidade e a polissemia ainda anuladas. Não há espaço em cena para a discussão da autoria.

Em Sociedade dos Poetas Mortos e A Voz do Coração, a polissemia marca a autoridade, que se em muitos momentos fica revestida pelo autoritarismo, reafirmando o professor na posição de sujeito constituída sob a determinação da hierarquia da autoridade de saber, em outros momentos se oferece aos alunos na relação com o conhecimento. Nos dois filmes há brechas que desestabilizam a sobredeterminação do professor pela posição de sujeito constituída pela hierarquia da autoridade de saber.

A cena recortada e analisada por Fedatto e Machado em A Voz do Coraçãoapresenta o professor de música na sala de aula agrupando os alunos de acordo com seus timbres de voz.São todos meninos e para essa seleção o professor pede a cada um que cante uma canção à sua escolha. Vemos os mais diferentes tipos físicos vestindo as mais variadas roupas, cantando as mais diversas canções, num conjunto heteróclito de rostos, músicas e letras. Fica ressaltada a enorme diversidade entre os meninos agregados no orfanato no qual se passa a história, diversidade que vai sendo organizada segundo a estrutura de um coral. No processo da seleção, um garoto diz não conhecer canção alguma e outro é muito desafinado. Eles recebem as funções de "assistente chefe de coral" e "estante de partitura" respectivamente. 

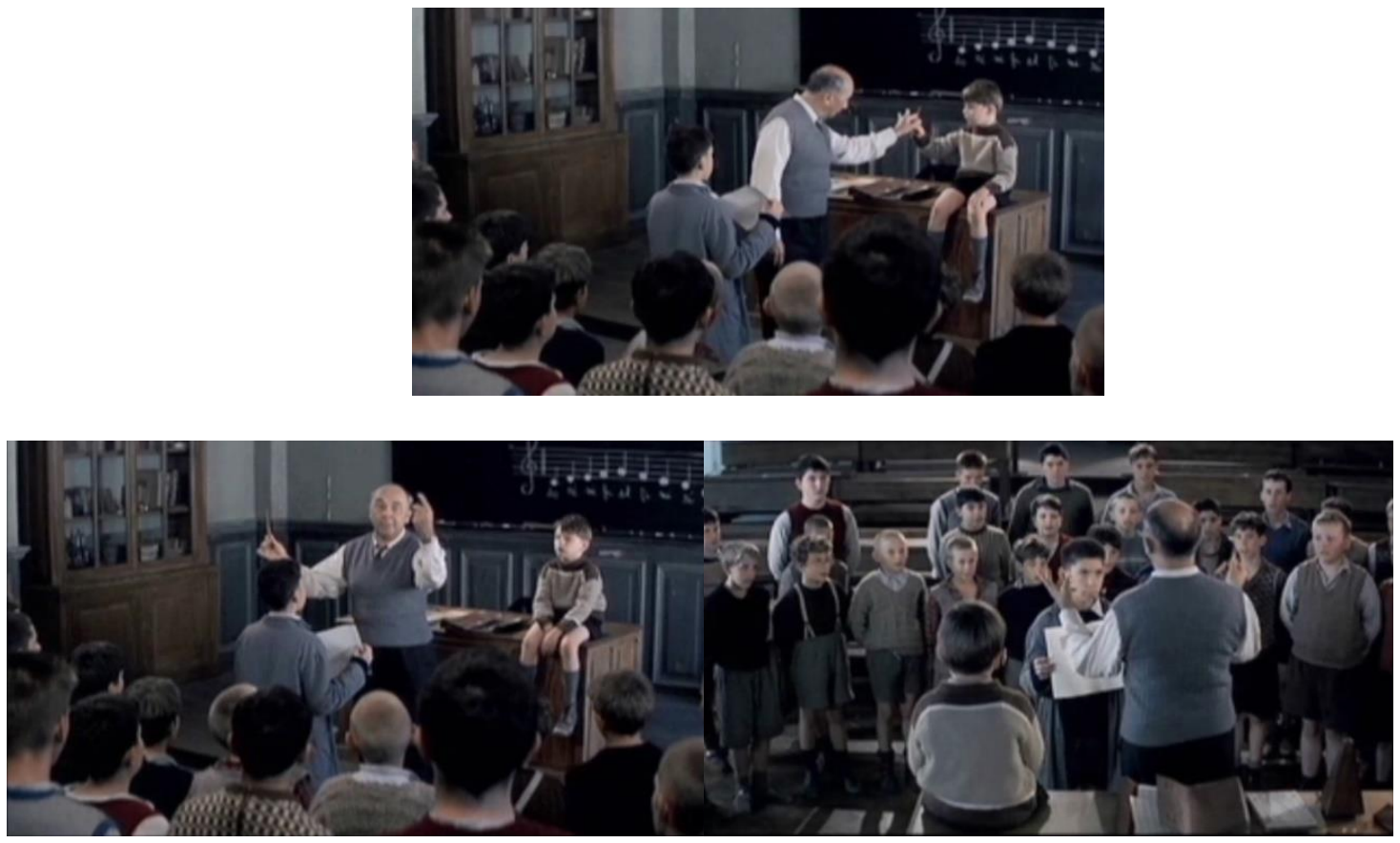

Em Sociedade dos Poetas Mortos,Fedatto e Machado recortam duas cenas, das quais retomo aquela em que o professor subverte os valores impostos por uma tradição literária positivista, ordenando aos alunos que rasguem a introdução do livro adotado por considerar o método proposto pelo autor um insulto à poesia, um "excremento" que deve ir para o lixo. Levando essa sua formulação à prática, insiste para que os alunos joguem as páginas no lixo. Depois do estranhamento da sala e de bastante resistência por parte de alguns, os alunos vão aderindo e jogam no lixo as páginas rasgadas. O professor os reúne num círculo e, agachado no meio deles,cita Whitman para ressaltar o valor da poesia na vida e a importância de que todos contribuam com um verso. Termina perguntando aos alunos qual será o verso de cada um.

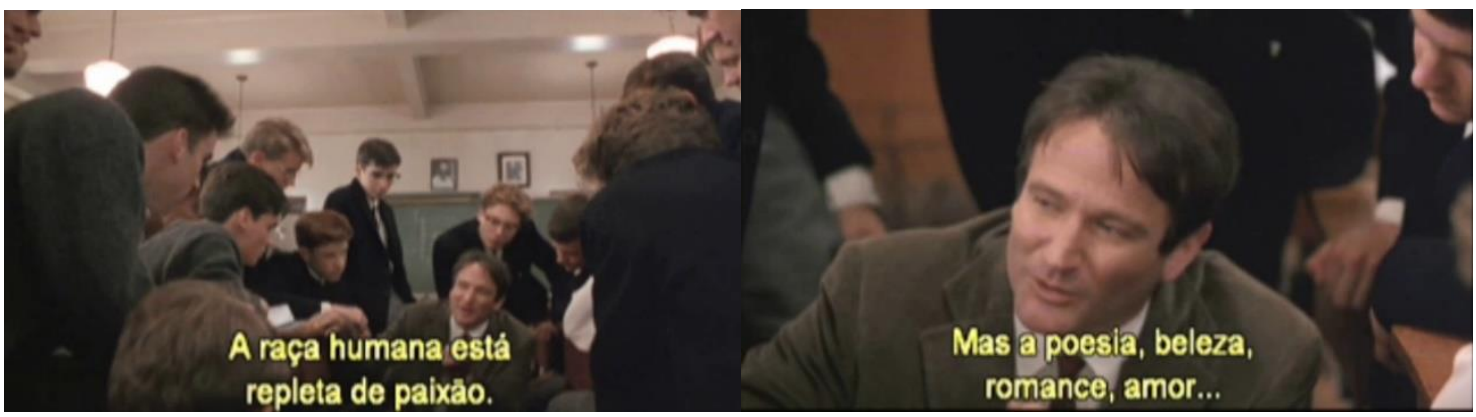




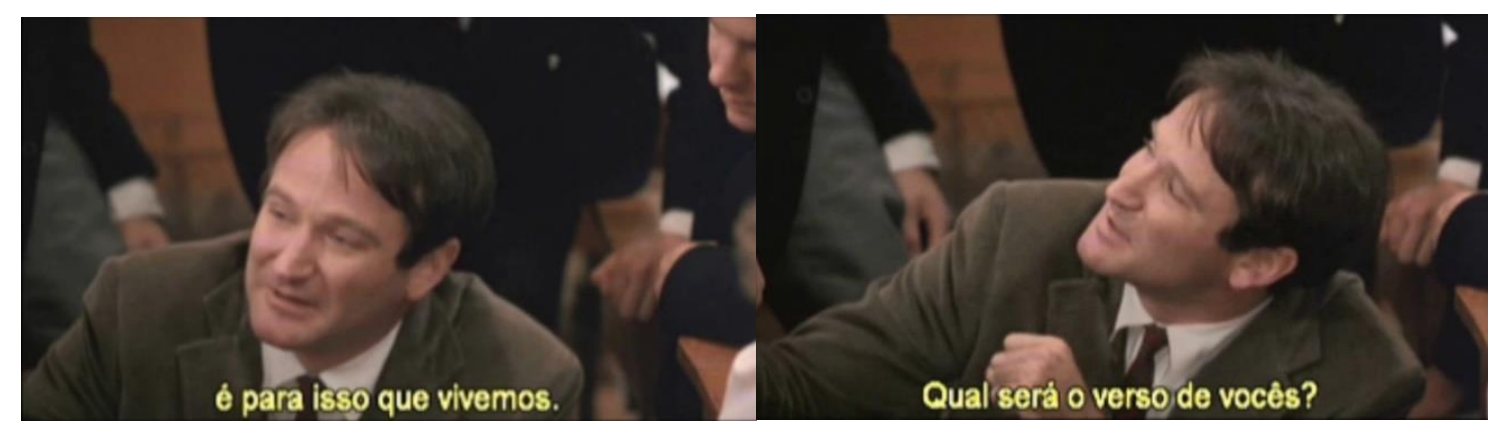

No movimento entre as posições de sujeito que constituem o professor nas cenas recortadas deA voz do coração e Sociedade dos Poetas Mortos, os sentidos de autoridade jogam entre o autoritarismo e a responsabilizaçãode maneira interessante: os dois professores são autoritários ao dizer aos alunos o que fazer, sem espaço para negociações, são autoritários em suas opiniões e nas propostas apresentadas, e ao mesmo tempoestabelecem uma interlocução direta com os alunos, mostrando o quanto são imprescindíveis para que a relação com o conhecimento se estabeleça.

\section{AUTORIA E EQUÍVOCO: FECHANDO CONSIDERAÇÕES}

A tentativa de acolhimento dos dois alunos que não se integraram ao coral como cantores, a pergunta lançada aos alunos sobre o verso com que darão sua contribuição. A autoridade se mostra equívoca, sustentada pela contradição entre a hierarquia da autoridade de saber que não abandona o professor e a importância de que o desejo de saber irrompa no aluno e o conhecimento se produza numa relação de apropriação e responsabilização.

Nos fotogramas analisados, é significativa a remissão do intradiscurso ao interdiscurso ${ }^{3}$.Observamos,nas formulações visuais desses fotogramas,composições entre alunos e professor que, quando remetidas à memória do dizer, produzem imagens inusitadas da sala de aula: o assistente chefe de coral sentado sobre a mesa do professor, o professor agachado em meio aos alunos. Uma reorganização espacial das fronteiras que visibiliza a desestabilização simbólica da dicotomia entre professor e aluno.

Em A voz do coração e Sociedade dos Poetas Mortos apossibilidade da autoria se faz presente pelo funcionamento do equívoco na autoridade.

${ }^{3}$ Cf. Lagazzi (2013b, 2014). 
Quero reiterar o que julgo ser uma distinção importante para a reflexão sobre o conceito de posição de sujeito: a diferença entre a posição institucional, definida pelo lugar institucionalmente ocupado pelo sujeito, e a posição de sujeito, constituída ideologicamente e determinada pelo pré-construído. Nesta retomada da discussão sobre a autoria, o foco no equívoco me permitiu tocar nesse ponto sensível do dispositivo discursivo. Um investimento teórico e analítico. Teoria e prática em relação dialética.

\title{
THE AUTHORSHIP IN THE MISCONCEPTED LINK OF SUBJECT POSITION
}

\begin{abstract}
The identification of students and professors in different subject positions is the major point of interest of this work, which can be synthesized in the main question: what positions are the ones that build up the teaching practice scenario? Using as theoretical-methodological the Materialist perspective of the Discourse Analysis, the author based herself on Pêcheux, Orlandi, Gallo, Pfeiffer, Fedatto and Machado. Considering the teaching practice conditions, the author interweaves the concept of subject position and the misconception notion in order to understand the production of knowledge as an authorship practice. The author points out the necessary search conditions so that the desire of knowlrdged and the identification with the knowledge are in conflict with the hierarchy of the knowledge's authority, so that the ownership of this authority becomes a process in which both subjects, the professors and the students, are responsible through the senses.
\end{abstract}

Keywords: Authorship; Misconception; Speech; Education; Subject Position

\section{LA AUTORÍA EN EL ENLACE EQUÍVOCO DE LAS POSICIONES DE SUJETO}

\section{Resumen}

La identificación de alumnos y profesores en diferentes posiciones de sujeto es elpunto central abordado en este texto, cuya preocupación principal puede sintetizarse en la pregunta: ¿qué posiciones son ésas que componen el escenario de la práctica docente? Teniendo como perspectiva teórico-metodológica el Análisis del Discurso Materialista, la autora se 
fundamenta en Pêcheux, Orlandi, Gallo, Pfeiffer, Fedatto y Machado. Considerando las condiciones de producción de la práctica docente, la autora en trelaza el concepto de posición de sujeto y la noción de equívoco para comprender la producción del conocimiento como gesto de autoría. Señala, en ese sentido, la necesaria búsqueda de condiciones para que el deseo de saber y laidentificaciónconelconocimientoesténencontradicciónconlajerarquía de la autoridad de saber, de modo que la apropiación de esa autoridad pase a ser un proceso de responsabilización de los sujetos profesores y alumnos por los sentidos.

Palavras clave: Autoría; Equívoco; Discurso; Ensenãnza; Posición de sujeto

\section{REFERÊNCIAS}

ALTHUSSER, Louis. Freud e Lacan. Marx e Freud. Rio de Janeiro: Graal, 1984.

FEDATTO, C. \& MACHADO, C. O muro, o pátio e o coral ou os sentidos no/do professor. In: BOLOGNINI, C.Z. (org.). O cinema na escola. Campinas: Mercado de Letras, 2007.

GALLO, Solange Leda. Discurso da escrita e ensino. Campinas: Editora da Unicamp, 1992.

LAGAZZI, Suzy. Delimitações, inversões, deslocamentos em torno do Anexo 3. In: LAGAZZI, S.; ROMUALDO, E.C.; TASSO, I. (Orgs.). Estudos do Texto e do Discurso. $O$ discurso em contrapontos: Foucault, Maingueneau, Pêcheux. São Carlos: Pedro \& João, $2013 \mathrm{a}$.

A imagem do corpo no foco da metáfora e da metonímia. REDISCO, V. 2., n.1, jan./jun. 2013. Vitória da Conquista: Edições UESB, 2013b. p.104-110.

Metaforizações metonímicas do social. In: ORLANDI, E. (org.). Linguagem, sociedade, políticas. Pouse Alegre: UNIVÁS; Campinas: RG Editores, 2014. p.105-112.

LAGAZZI-RODRIGUES, Suzy. A sala de aula e o alhures: circulando pela linguagem entre práticas e teorias. Letras ${ }^{\circ}{ }^{27}$. M.C.Corrêa e S.H.L.do Nascimento (orgs.). Santa Maria: UFSM / Centro de Artes e Letras / PPGL. Jul-Dez de 2003.

LAGAZZI-RODRIGUES, Texto e Autoria. In: Introdução às Ciências da Linguagem. Discurso e Textualidade.E.Orlandi e S.Lagazzi-Rodrigues (orgs.). Campinas: Pontes, 2006. p.83-103.

ORLANDI, Eni. A linguagem e seu funcionamento. As formas do discurso. São Paulo: Brasiliense, 1983.

Discurso e leitura. São Paulo: Cortez; Campinas: Editora da Unicamp, 1988. 
Autoria e Interpretação. Petrópolis: Vozes, 1996.

PÊCHEUX, Miguel. O discurso: estrutura ou acontecimento. Campinas: Pontes, 1990.

PFEIFFER, Claudia. Que autor é este? Tese de Doutorado, IEL/Unicamp, 1995.

Data de recebimento: 01/04/2015

Data de aceite: 16/06/2015 